\title{
Downregulation of Lgr6 inhibits proliferation and invasion and increases apoptosis in human colorectal cancer
}

\author{
FEI WANG ${ }^{1,2}$, CHUN-QIAN DAI ${ }^{2}$, LI-RONG ZHANG ${ }^{2}$, CAO BING $^{2}$, JUN QIN $^{1}$ and YI-FEI LIU ${ }^{3}$ \\ ${ }^{1}$ Department of General Surgery, The Affiliated Hospital of Nantong University, Nantong, Jiangsu 226000; \\ ${ }^{2}$ Department of General Surgery, Rudong No. 2 People's Hospital, Rudong, Jiangsu 226400; \\ ${ }^{3}$ Department of Pathology, The Affiliated Hospital of Nantong University, Nantong, Jiangsu 226000, P.R. China
}

Received October 30, 2017; Accepted March 30, 2018

DOI: $10.3892 /$ ijmm.2018.3633

\begin{abstract}
The aim of the present study was to analyze the role of leucine-rich repeat-containing G-protein coupled receptor 6 (Lgr6) in the proliferation and invasion of colorectal cancer (CRC) cells, and to investigate its possible mechanisms. The expression of Lgr6 in CRC tissues was observed by real time-quantitative polymerase chain reaction and western blotting. Then cell viability, apoptosis and cell invasion was measured by MTT, flow cytometry or Matrigel-Transwell system, respectively in CRC cells after transfected with Lgr6 siRNA or Lgr6 vector. Furthermore, the expression of apoptosis-associated protein and PI3K/AKT signaling (phosphorylated-PI3K, phosphorylated-AKT, t-PI3K, t-AKT) were measured by real-time PCR/or western blot analysis. The results demonstrated that the level of Lgr6 was higher in CRC tissues than that in adjacent tissues, and Lgr6 overexpression increased CRC proliferation, and invasion of CRC cells in vitro. Notably, suppressing the expression of Lgr6 in CRC cells increased the expression of B-cell lymphoma-2 (Bcl-2)-associated X protein and caspase-3, but decreased the expression of $\mathrm{Bcl}-2$ at the mRNA and protein levels. Lgr6 also had the ability to regulate the phosphoinositide 3-kinase/AKT signaling pathway. It was concluded that Lgr6 has a tumor-promoting role in the development of $\mathrm{CRC}$, and may serve as a potential diagnostic and prognostic biomarker for the disease.
\end{abstract}

\section{Introduction}

Colorectal cancer (CRC) is one of several types of malignant tumor with the highest cure rate $(1,2)$. In previous years, the

Correspondence to: Dr Jun Qin, Department of General Surgery, The Affiliated Hospital of Nantong University, 20 Xi-Si Street, Nantong, Jiangsu 226000, P.R. China

E-mail: youyi701@163.com

Dr Yi-Fei Liu, Department of Pathology, The Affiliated Hospital of Nantong University, 20 Xi-Si Road, Nantong, Jiangsu 226000, P.R. China

E-mail: ntdxliuyifei@sina.com

Key words: colorectal cancer, leucine-rich repeat-containing G-protein coupled receptor 6, proliferation, migration, phosphoinositide 3-kinase/AKT signaling pathway morbidity and mortality rates of CRC have significantly increased as a result of an aging population, and changes in eating habits and lifestyles (3). The development of distant metastasis is a main cause of cancer-associated mortality in patients with CRC (4). Biomarkers, including CEA and CA19-9, have failed to detect CRC in its early stages (5), and there is a less sensitive marker for the prognosis of CRC; therefore, treatment targets and predictive biomarkers are urgently required.

The proteins coded by the leucine-rich repeat-containing G-protein coupled receptor ( $L g r) 4 / 5 / 6$ family are G-protein-coupled receptors, which comprise leucine-rich repeats and have homology with glycoprotein hormone receptor (6-8). As stem cell markers, these genes have been examined in multiple organs, including the skin, liver and intestines, for several years (8). Lgr ligands are R-spondin (RSPO) ligands, and previous reports have demonstrated that Lgr receptors can activate $\mathrm{Wnt} / \beta$-catenin signaling by binding to RSPO ligands (9-12). It is known that the $\mathrm{Wnt} / \beta$-catenin pathway is important in CRC tumorigenesis, and that aberrant activation of the Wnt pathway is associated with $\sim 90 \%$ of cases of CRC in humans $(13,14)$; therefore, we hypothesized that the abnormal expression of $\mathrm{Lgr}$ is associated with CRC tumorigenesis.

Several previous studies have suggested that Lgr5 negatively regulates the Wnt pathway, which was observed in CRC tumors $(15,16)$. The expression level of Lgr5 was also increased in gastric cancer (GC), which was associated with growth and node metastasis (17), and patients with $\operatorname{Lgr5}^{+}$ GC had a poorer prognosis, compared with those with $\operatorname{Lgr5}^{-} \mathrm{GC}$ (18). The overexpression of $\operatorname{Lr} 5$ was shown to promote the development of CRC, and the silencing of Lgr5 reduced the proliferation, migration and colony formation in SW480 and HT-29 cells (19). Although the expression pattern of Lgr5 in CRC has been investigated, the role of Lgr6 in CRC remains unresolved. However, on analyzing the structures of Lgr5 and Lgr6, it was identified that they share $~ 50 \%$ sequence homology (7), and a previous study suggested that Lgr6 is a potential tumor-associated gene (20). Lgr6 has been reported as a tumor suppressor gene (11) and a susceptibility gene (21). The exact roles of Lgr receptors vary due to the different expression patterns and/or interactions of the gene and RSPO family members in a given cellular context (16). As a stem-cell marker, Lgr6 has been reported in multiple studies in the taste buds (22), lungs (23) and skin (24), however, its role in CRC 
remains to be fully elucidated. Therefore, the present study aimed to obtain this information by further examining the putative biological significance of Lgr6 in CRC.

\section{Materials and methods}

Patients and tissue samples. The present study was approved and supervised by the Research Ethics Committee of the Affiliated Hospital of Nantong University (Nantong, China). Written informed consent was obtained from all patients. Paired CRC and adjacent normal colon tissue samples were obtained between October 2015 and December 2017 from 45 patients who underwent primary surgical CRC resection at the hospital. The patients included 20 women and 25 men, aged between 37 and 83 years. A total of 13 patients had World Health Organization (WHO) grade (25) T1 disease, 14 patients had WHO grade T2 disease, and 14 patients had WHO grade T3, 4 patients had WHO grade T4 disease. All tissue samples were immediately frozen in liquid nitrogen until use.

Cell lines, in vitro culture, plasmids and transfection. HCT-116 and SW480 cells were purchased from the Type Culture Collection of the Chinese Academy of Sciences (Shanghai, China). The cells were maintained in RPMI-1640 (GE Healthcare Life Sciences, Logan, UT, USA) supplemented with $10 \%$ fetal bovine serum (FBS; Gibco; Thermo Fisher Scientific, Inc., Waltham, MA, USA), and incubated at $37^{\circ} \mathrm{C}$ in a $5 \% \mathrm{CO}_{2}$ atmosphere. The pcDNA3.1 vector containing a wild-type $L g r 6$ insert was provided by General Biosystems (Anhui, China). The sequences of small interfering RNAs (siRNAs) for Lgr6 were purchased from GenePharma Co., Ltd. (Suzhou, China). The siRNA sequences were as follows: Lgr6 siRNA1, sense, 5'-CCCUGGAUCUUA GCUGGAATT-3' and antisense, 5'-UUCCAGCUAAGAUCC AGGGTT-3'; Lgr6 siRNA2, sense, 5'-GCAUUCCAGUACCUG CCUATT-3' and antisense, 5'-UAGGCAGGUACUGGAAUG CTT-3'; Lgr6 siRNA3, sense, 5'-CCUGGAACUGUCUCACAA UTT-3' and antisense, 5'-AUUGUGAGACAGUUCCAGGTT-3'; negative control, sense, 5'-UUCUCCGAACGUGUCACG UTT-3' and antisense, 5'-ACGUGACACGUUCGGAGAATT-3'. The cells were transfected with Lgr6 siRNA, negative control (siCtrl), or pcDNA3.1-Lgr6 cDNA at $~ 50 \%$ density using Lipofectamine 3000 (Invitrogen; Thermo Fisher Scientific, Inc.) according to the manufacturer's protocol.

Reverse-transcription-quantitative polymerase chain reaction $(R T-q P C R)$ analysis. Total RNA was extracted from the cells or tumor tissues using TRIzol reagent (Invitrogen; Thermo Fisher Scientific, Inc.) and $2 \mu \mathrm{g}$ total RNA from each sample was used for cDNA synthesis using a cDNA synthesis kit (Tiangen, Beijing, China). The qPCR analysis was performed using SYBR-Green (Invitrogen) according to the manufacturer's protocol, the reaction system contained $2 \mu \mathrm{l}$ cDNA, $0.5 \mu 1$ forward primer $(10 \mathrm{nM}), 0.5 \mu 1$ reverse primer $(10 \mathrm{nM})$, $10 \mu \mathrm{l}$ SYBR-Green buffer and $7 \mu \mathrm{l}$ distilled water. Data collection was conducted using an ABI 7500 (Applied Biosystems; Thermo Fisher Scientific, Inc.). The cycling conditions were as follows, $50^{\circ} \mathrm{C}$ for $2 \mathrm{~min}$ and $95^{\circ} \mathrm{C}$ for $2 \mathrm{~min}$, followed by 40 cycles at $95^{\circ} \mathrm{C}$ for $15 \mathrm{sec}$ and $60^{\circ} \mathrm{C}$ for $1 \mathrm{~min}$. The conditions for melt curve analysis were $95^{\circ} \mathrm{C}$ for $15 \mathrm{sec}, 60^{\circ} \mathrm{C}$ for $1 \mathrm{~min}$ and $95^{\circ} \mathrm{C}$ for $15 \mathrm{~min}$. The primer sequences were as follows: B-cell lymphoma-2 (Bcl-2), sense, 5'-CAGGAAACGGCCCGG AT-3' and antisense, 5'-CTGGGGCCTTTCATCCTCC-3'; Bcl-2-associated X protein (Bax), sense, 5'-GGGTTGTCG CССТTTTCTAC-3' and antisense, 5'-CTGGAGACAGGG ACATCAGT-3'; caspase-3, sense, 5'-TGCTATTGTGAGGCG GTTGTAG-3' and antisense, 5'-GGCACACCCACCGAA AAC-3'; Lgr6, sense, 5'-TGACGGCTTACCTGGACCTCA-3' and antisense, 5'-AGAGAATGCTTGTCCTGGGATG-3'; GAPDH, sense, 5'-GAAGGTGAAGGTCGGAGTC-3' and antisense, 5'-GAAGATGGTGATGGGATTTC-3'. The relative expression of each gene was quantified using the $2^{-\Delta \Delta C q}$ method (26), and GAPDH was used as the internal control.

Western blot analysis. Whole-cell extracts from the cultured cells or tissues were prepared and subjected to western blot analysis using RIPA lysis buffer (Beyotime Institute of Biotechnology, Shanghai, China). Total protein $(50 \mu \mathrm{g})$ was resolved by $12 \%$ sodium dodecyl sulfate polyacrylamide gel electrophoresis and transferred onto polyvinylidene fluoride membranes (EMD Millipore, Billerica, MA, USA). The membranes were blocked with $5 \%$ skimmed milk powder for $1 \mathrm{~h}$ at room temperature. The membranes were then incubated with primary antibodies overnight at $4^{\circ} \mathrm{C}$, and all primary antibodies were purchased from Abcam (Cambridge, MA, USA) as follows: Rabbit anti-Lgr6 (cat.no. ab205760; dilution 1:2,000), mouse anti- $\beta$-actin (cat. no. ab8226; dilution 1:10,000), rabbit anti-pan-AKT (cat. no. ab8805; dilution 1:500), Rb anti-pan-AKT (phospho-T308; cat. no. ab38449; dilution 1:800), rabbit anti-Bcl-2 (cat. no. ab32124; dilution 1:1,000), rabbit anti-Bax (cat. no. ab32503; dilution 1:1,000), and rabbit anti-active-caspase-3 (cat. no. ab2302; dilution 1:200). The membranes were washed three times with PBS-Tween-20 for $10 \mathrm{~min}$ and then incubated with the goat anti-mouse (cat. no. ab6789; dilution 1:5,000) or goat anti-rabbit (cat. no. ab6721; dilution 1:10,000) secondary antibody for $1 \mathrm{~h}$ at room temperature. The blots were developed using an enhanced chemiluminescence Western Blotting Detection System (Invitrogen) and X-ray film. The band density was qualified by ImageJ software (National Institutes of Health, Bethesda, MD, USA).

Cell invasion assay. The invasive capability of the cells was determined using Matrigel-coated invasion chambers with a pore size of 0.8-mm (BD Biosciences, San Jose, CA, USA). The cells were resuspended with $2 \% \mathrm{FBS}$, and $\sim 1 \times 10^{5}$ cells were transfected with Lgr6 siRNA (siLgr6), negative control (siCtrl), or pcDNA3.1-Lgr6 cDNA added to the inner chamber; the outer chamber contained $20 \% \mathrm{FBS}$. Following incubation at $37^{\circ} \mathrm{C}$ in $5 \% \mathrm{CO}_{2}$ for $24 \mathrm{~h}$, the cells on the upper surface of the inner chamber were removed with cotton swabs. The invaded cells that adhered to the lower surface of the membrane were fixed, stained with crystal violet, and observed through an optical microscope (TS100F; Nikon Corporation, Tokyo, Japan).

Cell proliferation assay. A 3-(4,5-dimethythiazol-2-yl)-2,5diphenyl tetrazolium bromide (MTT) assay was performed to measure cell proliferation. Briefly, $\sim 5,000$ cells per well were cultured in 96-well plates for $24 \mathrm{~h}$ and transfected with Lgr6 siRNA, negative control, or pcDNA3.1-Lgr6 cDNA. Cell proliferation was determined $48 \mathrm{~h}$ later. MTT solution $(5 \mathrm{mg} / \mathrm{ml}$ 
Table I. Association between the expression of Lgr6 and clinicopathological factors.

\begin{tabular}{|c|c|c|c|c|c|}
\hline Clinicopathological characteristic & $\mathrm{n}$ & Low expression $\mathrm{n}(\%)$ & High expression $\mathrm{n}(\%)$ & $\chi^{2}$ & P-value \\
\hline Total & 117 & & & & \\
\hline Sex & & & & 0.326 & 0.700 \\
\hline Male & 71 & $30(42.25)$ & $41(57.75)$ & & \\
\hline Female & 46 & $17(36.96)$ & $29(63.04)$ & & \\
\hline Age (years) & & & & 0.512 & 0.572 \\
\hline$<60$ & 57 & $21(36.84)$ & $36(63.16)$ & & \\
\hline$\geq 60$ & 60 & $26(43.33)$ & $34(56.67)$ & & \\
\hline Differentiation grade & & & & 6.970 & 0.009 \\
\hline Middle and high & 81 & $39(48.15)$ & $42(51.85)$ & & \\
\hline Low & 36 & $8(22.22)$ & $28(77.78)$ & & \\
\hline Tumor diameter $(\mathrm{cm})$ & & & & 0.958 & 0.426 \\
\hline$<3$ & 17 & $5(29.41)$ & $12(70.59)$ & & \\
\hline$\geq 3$ & 100 & $42(42.00)$ & $58(58.00)$ & & \\
\hline T category & & & & 11.796 & 0.003 \\
\hline T1 & 9 & $5(55.56)$ & $4(44.44)$ & & \\
\hline $\mathrm{T} 2$ & 48 & $27(56.25)$ & $21(43.75)$ & & \\
\hline $\mathrm{T} 3+\mathrm{T} 4$ & 60 & $15(25.00)$ & $45(75.00)$ & & \\
\hline $\mathrm{N}$ stage & & & & 15.378 & $<0.001$ \\
\hline No & 52 & $27(51.92)$ & $25(48.08)$ & & \\
\hline N1 & 35 & $17(48.57)$ & $18(51.43)$ & & \\
\hline $\mathrm{N} 2$ & 30 & $3(10.00)$ & $27(90.00)$ & & \\
\hline 5-year survival & & & & 25.676 & $<0.001$ \\
\hline No & 39 & $3(7.69)$ & $36(92.31)$ & & \\
\hline Yes & 78 & $44(56.41)$ & $34(43.59)$ & & \\
\hline
\end{tabular}

High expression of Lgr6 was associated with poor differentiation, lymph node metastasis, and advanced clinical stage, but not with age, sex or tumor diameter. Lgr6, leucine-rich repeat-containing G-protein coupled receptor 6.

in PBS) was added to each well. The solution was incubated at $37^{\circ} \mathrm{C}$ for $4 \mathrm{~h}$, the medium was removed, and $150 \mu \mathrm{l}$ of dimethyl sulfoxide was added to each well. The absorbance of each well was measured at $490 \mathrm{~nm}$ using the Multiskan FC automated microplate reader (Thermo Fisher Scientific, Inc.).

Cell apoptosis assay. Cell apoptosis was evaluated by flow cytometry using an Annexin V-PE/7-AAD Apoptosis Detection kit (BD Biosciences) according to the manufacturer's protocol. Briefly, the transfected cells were harvested, washed twice in cold PBS, and resuspended in $500 \mu \mathrm{l}$ binding buffer. For staining, $5 \mu \mathrm{l}$ of Annexin V-PE and $5 \mu \mathrm{l}$ of 7-AAD were combined and gently mixed, and the cells were stained in the dark for $15 \mathrm{~min}$ at room temperature. The cells were immediately analyzed by flow cytometry.

Statistical analysis. The statistical analysis was performed using SPSS 17.0 (SPS, Inc., Chicago, IL, USA). The survival rate of patients with CRC was calculated using the Kaplan-Meier survival analysis method. Statistically significant differences were determined using one-way analysis of variance. The results are expressed as the mean \pm standard deviation. $\mathrm{P}<0.05$ was considered to indicate a statistically significant difference.

\section{Results}

Lgr6 is upregulated in human CRC tissues. To reveal the function of Lgr6 in CRC, its levels in CRC tissues and adjacent normal tissues were detected by western blotting or RT-qPCR analysis. The results indicated that the expression of Lgr6 in CRC tissues was significantly higher, compared with that in adjacent normal tissues (Fig. 1A-C). In addition, a high expression of Lgr6 was associated with poor differentiation, lymph node metastasis and advanced clinical stage, but not with age, sex or distant metastasis (Table I). The survival rate of patients with a high expression of Lgr6 was shorter, compared with that of patients with a low expression of Lgr6 (Fig. 2). Accordingly, the present study demonstrated that increased expression of Lgr6 is associated with the progression of CRC.

Downregulation of Lgr6 inhibits the proliferation of CRC cells in vitro. The HCT-116 and SW480 cells were transfected with Lgr6 siRNA with a different target sequence or negative control to determine the role of Lgr6 in CRC cells in vitro. As shown in Fig. 3A and B, the levels of Lgr6 were successfully reduced in the HCT-116 and SW480 cells when transfected with Lgr6 siRNA1 or Lgr6 siRNA3, respectively. Lgr6 


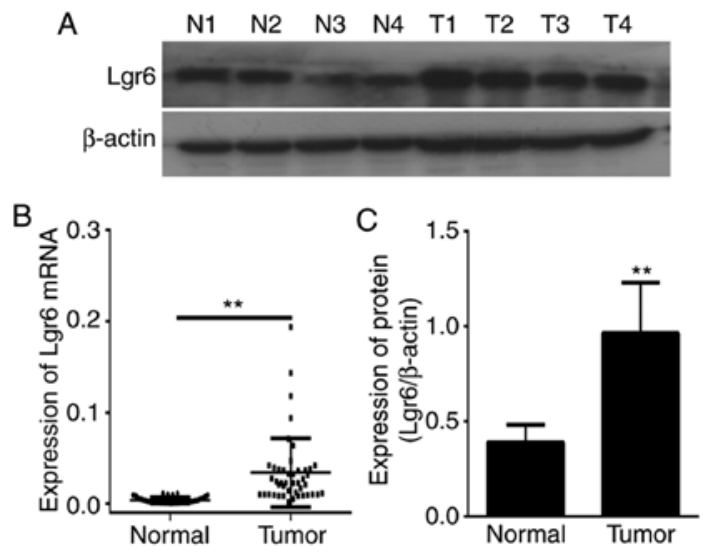

Figure 1. Expression of Lgr6 is increased in CRC. (A) Representative western blot analysis of Lgr6 protein in CRC (T1-T4) and paired normal tissues (N1-N4) from patients. $\beta$-actin was used as a loading control to normalize the protein levels of Lgr6 in each sample ( $\mathrm{n}=45)$. (B) Determination of mRNA levels of Lgr6 in CRC tissues and paired normal tissues by reverse transcription-quantitative polymerase chain reaction analysis $(n=45)$. (C) Quantification of protein levels of Lgr6. ${ }^{* *} \mathrm{P}<0.01$ vs. normal tissues. CRC, colorectal cancer; Lgr6, leucine-rich repeat-containing G-protein coupled receptor 6.
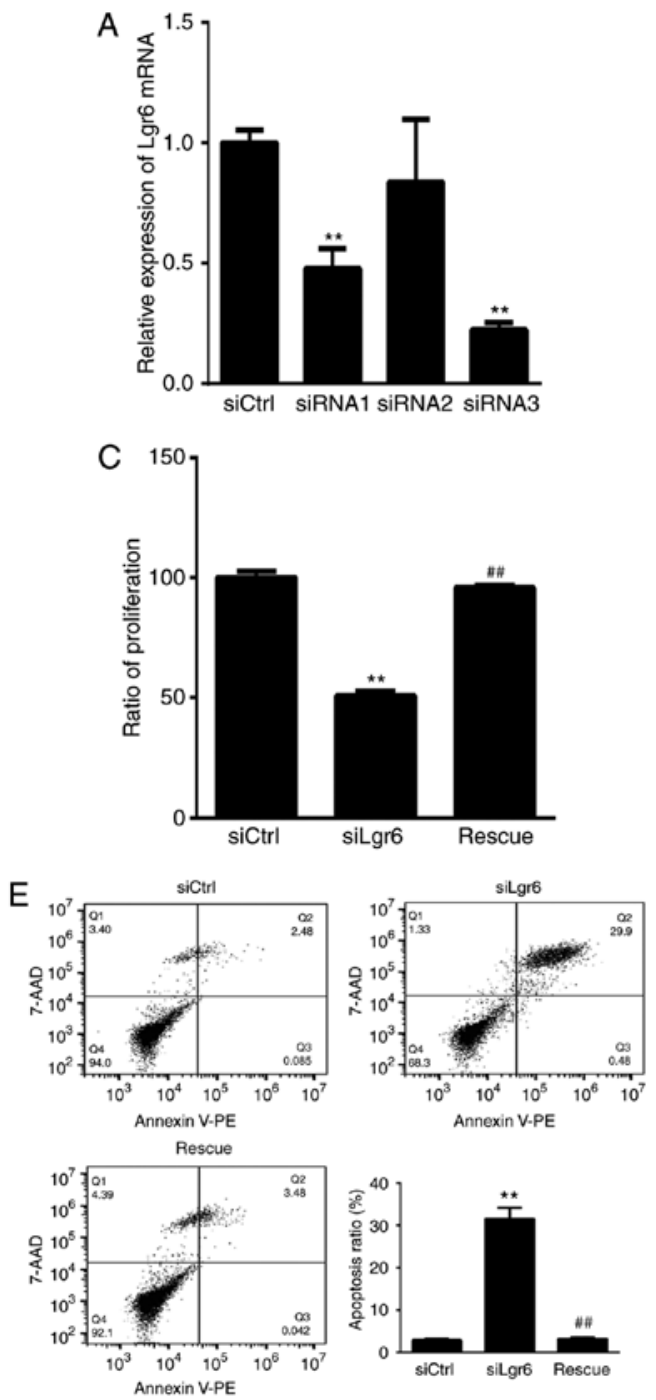

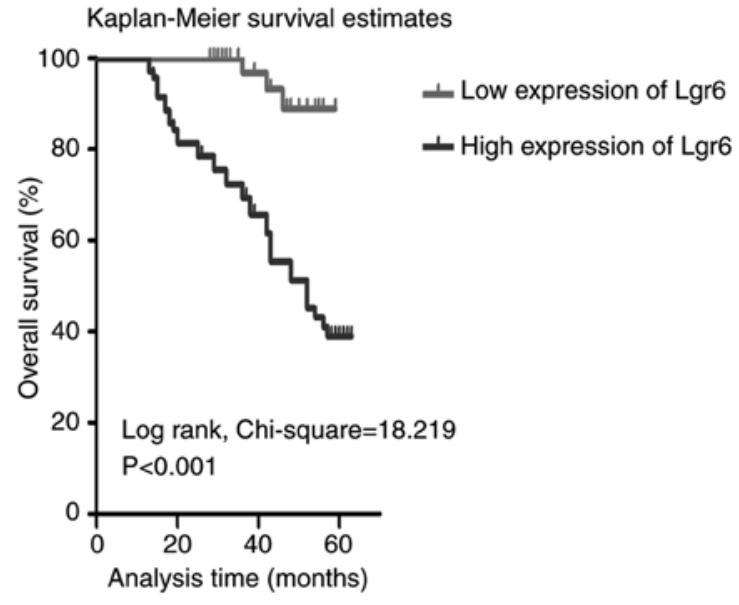

Figure 2. Kaplan-Meier survival curves for high vs. low expression of $\operatorname{Lgr6}$ in 117 patients with colorectal cancer. Patients with a high expression of $\operatorname{Lgr} 6$ had significantly shorter overall survival rates, compared with those with a low expression ( $\mathrm{P}=0.001)$. Lgr6, leucine-rich repeat-containing G-protein coupled receptor 6 .
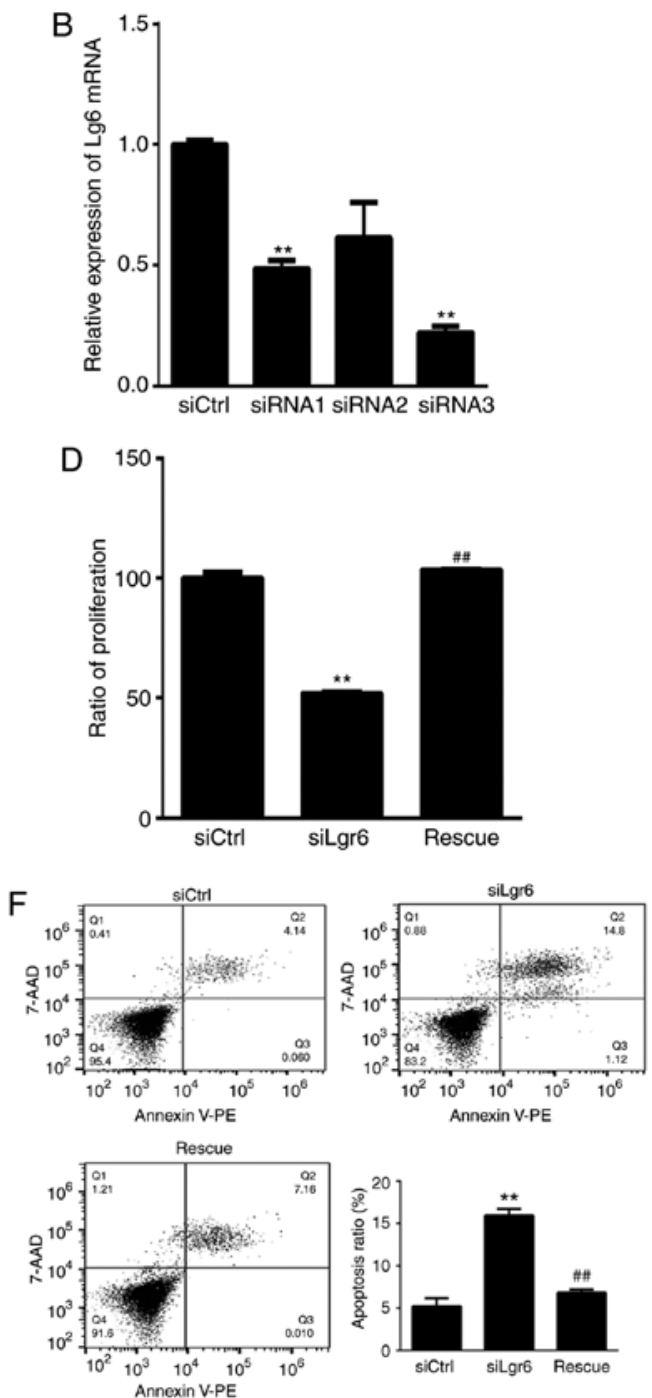

Figure 3. Silencing Lgr6 inhibits cell proliferation in colorectal cancer cell lines. (A) Expression of Lgr6 was determined in HCT-116 cells and (B) SW480 cells transfected with siCtrl or one of three Lgr6 siRNAs (siRNA1, siRNA2 and siRNA3). MTT analysis of (C) HCT-116 cells and (D) of SW480 cells. Flow cytometric analysis of (E) HCT-116 cells and (F) SW480 cells. ${ }^{* * *} \mathrm{P}<0.01$ vs. siCtrl group; ${ }^{\# \#} \mathrm{P}<0.01$ vs. siLgr6 group. Lgr6, leucine-rich repeat-containing G-protein coupled receptor 6; siRNA, small interfering RNA; siCtrl, negative control siRNA; siLgr6, cells transfected with Lgr6 siRNA3; MTT, 3-(4,5-dimethythiazol-2-yl)-2,5-diphenyl tetrazolium bromide; Rescue, cells with Lgr6-knockdown transfected with pcDNA3.1-Lgr6 cDNA. 

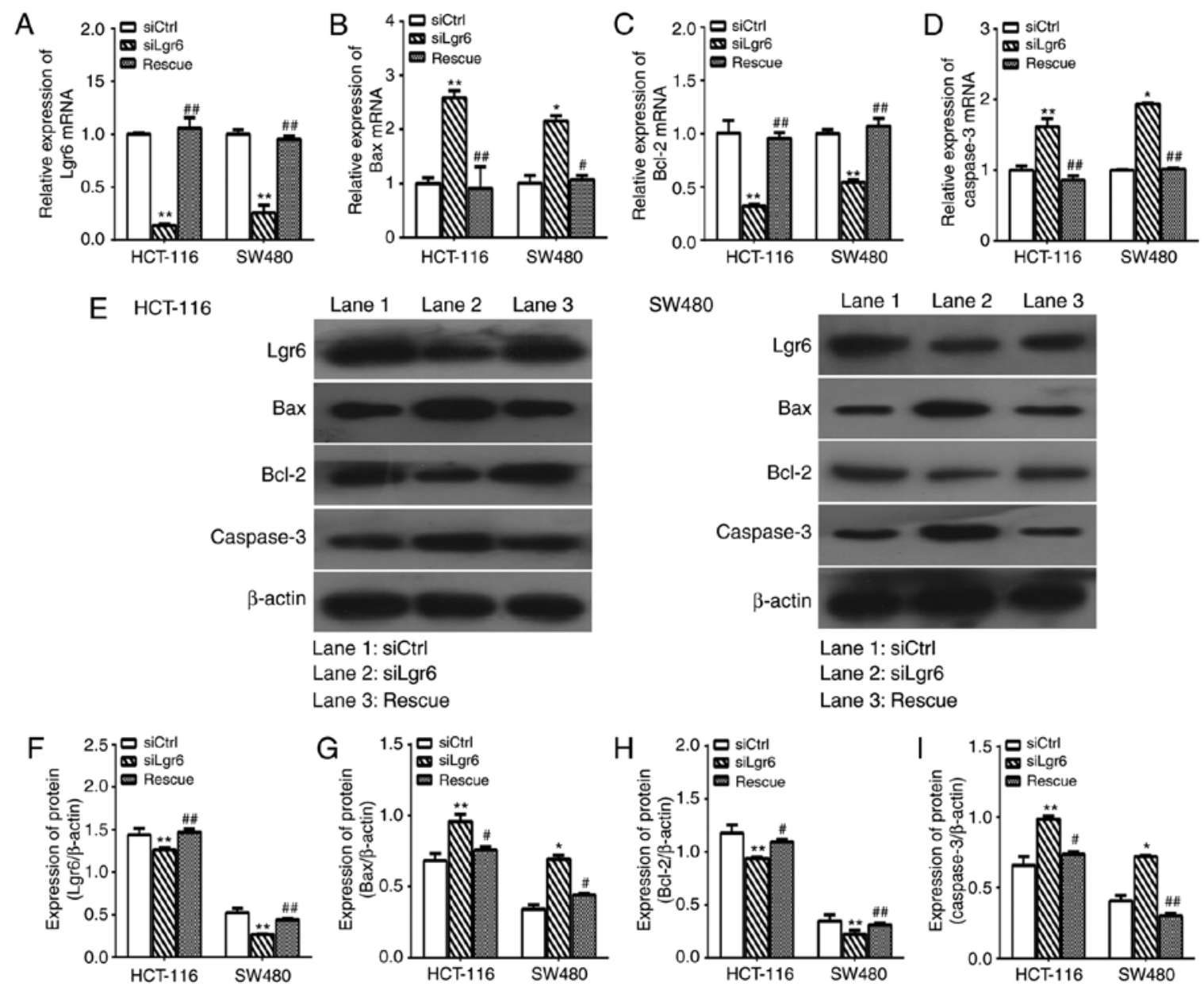

Figure 4. Knockdown of Lgr6 inhibits the expression of apoptosis-associated proteins in colorectal cancer cell lines. Reverse transcription-quantitative polymerase chain reaction analysis of mRNA levels of (A) Lgr6, (B) Bax, (C) Bcl-2 and (D) caspase-3 in HCT-116 and SW480 cells. (E) Western blot analysis of protein expression and quantification of (F) Lgr6, (G) Bax, (H) Bcl-2 and (I) caspase-3 in HCT-116 and SW480 cells. * $\mathrm{P}<0.05$ and *** $\mathrm{P}<0.01$ vs. siCtrl group; ${ }^{\#} \mathrm{P}<0.05$ and ${ }^{\# \#} \mathrm{P}<0.01$ vs. siLgr6 group. Lgr6, leucine-rich repeat-containing G-protein coupled receptor 6; siRNA, small interfering RNA; siCtrl, negative control siRNAs; siLgr6, cells transfected with Lgr6 siRNA3; Rescue Lgr6 knockdown cells transfected with pcDNA3.1-Lgr6 cDNA; Bcl-2, B-cell lymphoma 2; Bax, Bcl-2-associated X protein.

siRNA3 showed the optimal interference efficiency; therefore, this sequence was used for subsequent experiments. The MTT assay revealed that the knockdown of Lgr6 in HCT-116 and SW480 cells significantly decreased cell growth, and that the overexpression of Lgr6 in these knockdown cells rescued cell proliferation (Fig. 3C and D). Flow cytometric analysis was used to further identify the growth-inhibitory effects of Lgr6 siRNA. The results showed that Lgr6 siRNA induced the apoptosis of HCT-116 and SW480 cells following $48 \mathrm{~h}$ of transfection (Fig. 3E and F). In addition, western blot analysis was used to examine the expression of several proteins associated with apoptosis. As shown in Fig. 4, inhibition via Lgr6 siRNA in the HCT116 and SW480 cells elevated the expression of caspase- 3 and Bax at the (Fig. 4A-D) mRNA and (Fig. 4E-I) levels, whereas the expression of Bcl-2 was markedly downregulated. Collectively, these data suggested that the decreased cell number induced by Lgr6 siRNA was partly caused by enhanced cell apoptosis.

Downregulation of Lgr6 inhibits the invasion of CRC cells in vitro. Matrigel invasion assays were used to determine the invasive capabilities of Lgr6 in CRC cells. It was found that silencing Lgr6 in the HCT-116 and SW480 cells decreased the number of invasive cells, compared with that in the control cells (Fig. 5A-D). The overexpression of Lgr6 in these knockdown cells rescued cell invasion. These data indicated that Lgr6 was also involved in the invasion of CRC.

Downregulation of Lgr6 inhibits activation of the PI3K/AKT signaling pathway. It has been well documented that the $\mathrm{PI} 3 \mathrm{~K} / \mathrm{AKT}$ pathway is important in the proliferation and invasion of CRC (27-30); therefore, the present study investigated whether Lgr6 affected PI3K/AKT signaling in addition to Wnt/ $\beta$-catenin signaling. As shown in Fig. 6A-F, Lgr6-silencing significantly decreased the activation of $\mathrm{AKT} / \mathrm{PI} 3 \mathrm{~K}$ in the HCT-116 and SW480 CRC cells. These results suggested that Lgr6 may also be involved in activation of the PI3K/AKT pathway in CRC cells.

\section{Discussion}

The upregulation of Lgr6 has been confirmed in several types of cancer, including basaloid skin tumors (31) and gastric cancer (17). In the present study, it was demonstrated that Lgr6 

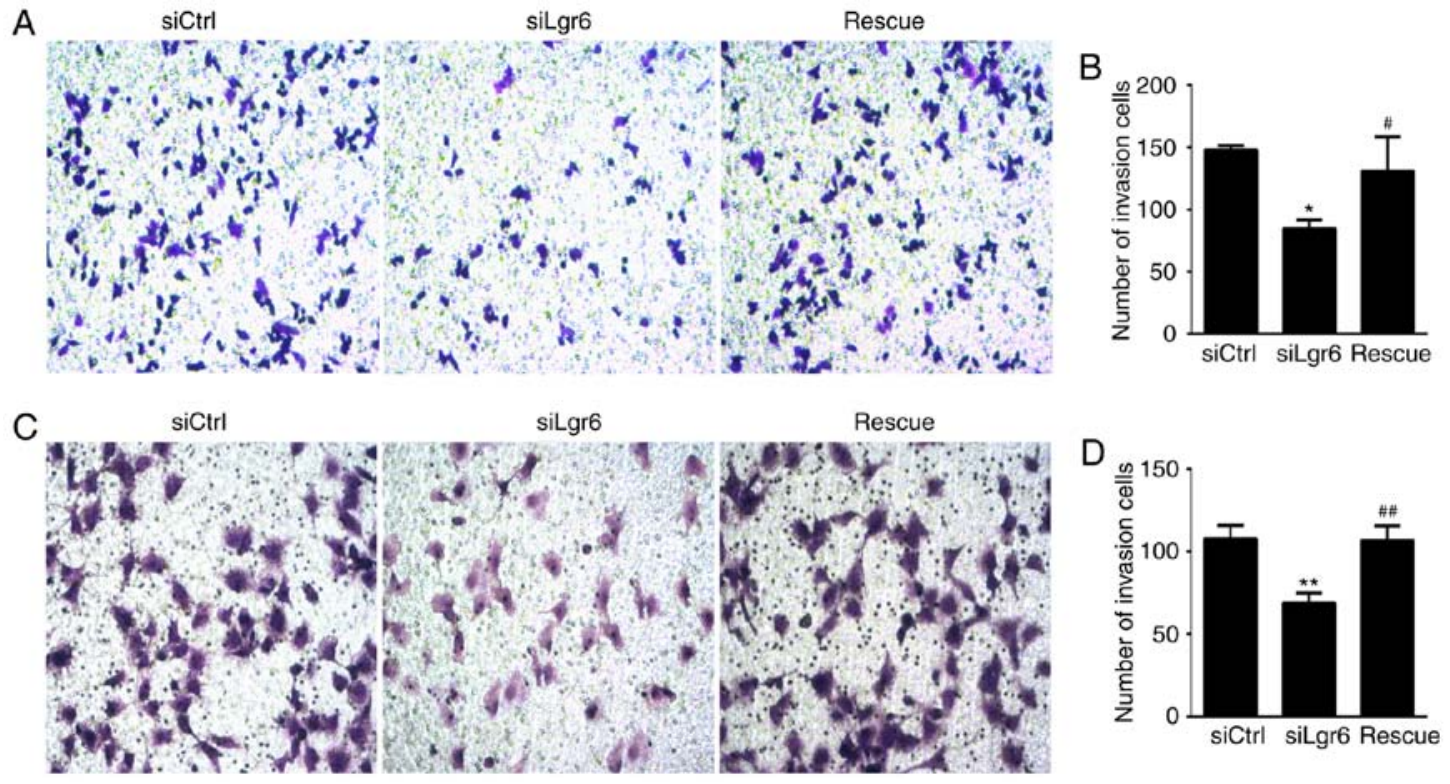

Figure 5. Knockdown of Lgr6 inhibits colorectal cancer cell invasion. Representative images of Transwell-Matrigel analysis in (A) HCT-116 with (B) quantification, and (C) SW480 cells with (D) quantification (magnification, x100). The cells penetrating through Matrigel were counted in five randomly selected fields. ${ }^{*} \mathrm{P}<0.05$ and ${ }^{* *} \mathrm{P}<0.01$ vs. siCtrl group; ${ }^{\#} \mathrm{P}<0.05$ and ${ }^{\# \#} \mathrm{P}<0.01$ vs. siLgr6 group. Lgr6, leucine-rich repeat-containing G-protein coupled receptor 6; siRNA, small interfering RNA; siCtrl, negative control siRNAs; siLgr6, cells transfected with Lgr6 siRNA3; Rescue, Lgr6 knockdown cells transfected with pcDNA3.1-Lgr6 cDNA.
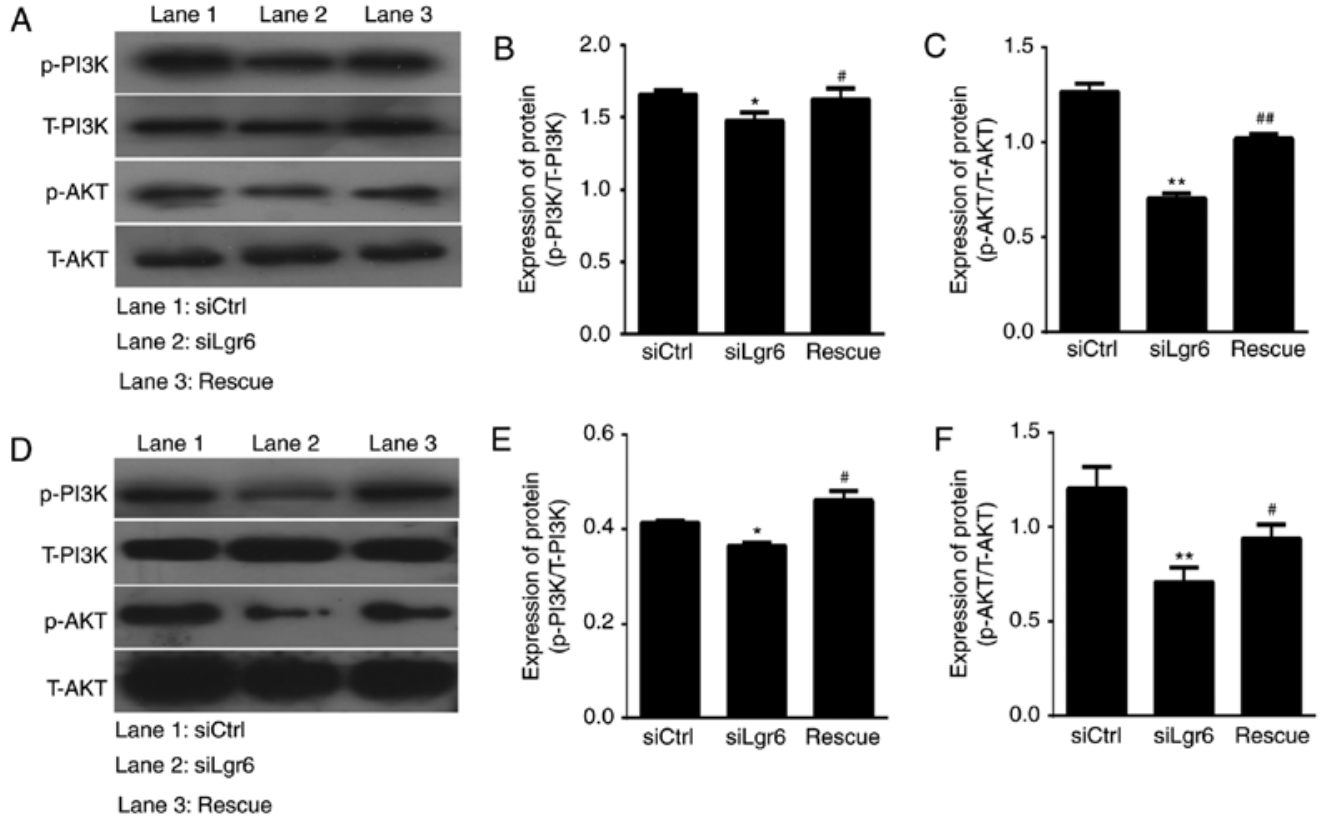

Figure 6. Knockdown of Lgr6 inhibits activation of the PI3K/AKT signaling pathway. (A) Western blot analysis of protein expression of t-PI3K/AKT, (B) p-PI3K and (C) p-AKT in HCT-116 cells. (D) Western blot analysis of protein expression of t-PI3K/AKT, (E) p-PI3K and (F) p-AKT in SW480 cells. ${ }^{*} \mathrm{P}<0.05$ and ${ }^{* *} \mathrm{P}<0.01$ vs. siCtrl group; ${ }^{\#} \mathrm{P}<0.05$ and ${ }^{\# \#} \mathrm{P}<0.01$ vs. siLgr6 groups. Lgr6, leucine-rich repeat-containing G-protein coupled receptor 6; siRNA, small interfering RNA; siCtrl, negative control siRNA; siLgr6, cells transfected with Lgr6 siRNA3; Rescue, Lgr6 knockdown cells transfected with pcDNA3.1-Lgr6 cDNA; PI3K, p-, phosphorylated; T-, total.

was upregulated in CRC tissues, and that high levels of $\operatorname{Lgr} 6$ in CRC were associated with tumor differentiation. $\mathrm{Lg} 6$ is also reported to be involved in several important cell processes, including proliferation, invasion and metastasis (11). Lgr6 mutation has been found in CRC, which has been suggested as one of the candidate cancer genes (32). Mokarram et al (33) found that the methylation of $\operatorname{Lgr} 6$ was stage-dependent and is thus associated with cell proliferation (7). In accordance with data in Table I and Fig. 2, the levels of Lgr6 were associated with tumor stage and the 5-year survival rate; however, the actual biological functions of $\operatorname{Lgr} 6$ and the underlying mechanisms in CRC remained to be fully elucidated. To address this problem, two CRS cell lines (HCT-116 and SW480), which express high levels of $\operatorname{Lgr} 6$, were used in the present study. 
The results of the present study showed that siRNA targeting Lgr6 in the HCT-116 and SW480 cells led to the inhibition of endogenous mRNA and protein levels of Lgr6 in vitro, in an efficient and specific manner. It was found that the downregulation of Lgr6 in HCT-116 and SW480 cells contributed to decreased cell invasion. These data suggested that Lgr6 is vital in the metastasis of CRC, which is consistent with previous findings in other cancer cells, including GC and lung cancer. In addition to a marker of adult stem cells, Lgr6 has been reported as a potential marker for cancer stem cells (8). The accumulation of Lgr6 in later stages retains cancer stem cell features, which are involved in self-renewal and poor differentiation of lung adenocarcinoma (34). Additional experiments demonstrated that the knockdown of Lgr6 in HCT-116 and SW480 cells significantly inhibited cell proliferation in vitro. These results were also found in CRC (19) when Lgr5 was silenced, which shares $~ 50 \%$ sequence homology with Lgr6. Rho GTPases are regulated by Lgr5 (35) and have been shown to be involved in cell cycle entry and progression (36). As targeting Rho GTPases provides a therapeutic opportunity for patients with cancer (36), further investigations are required to identify whether Rho GTPases are regulated by Lgr6 in CRC. In the present study, flow cytometric analysis demonstrated that Lgr6-silencing led to the apoptosis of HCT116 and SW480 cells. In accordance with these results, transfection with Lgr6 siRNA resulted in changes in apoptosis-associated proteins, including increased expression levels of caspase- 3 and Bax, and decreased expression of Bcl-2 in HCT-116 and SW480 cell lines. Taken together, these results indicated that $\operatorname{Lgr} 6$ was important in regulating the proliferation and invasion of CRC cells.

Previous studies have revealed that Lgr6 activates multiple signaling pathways, including the $\mathrm{Wnt} / \beta$-catenin pathway $(34,37)$; however, no studies have focused on its role in activating the PI3K/AKT pathway in CRC. In the present study, AKT/PI3K was inactivated when Lgr6 was inhibited by siRNA, indicating that the role of Lgr6 in CRC may partly depend on the PI3K/AKT pathway. PI3K/AKT is an important pathway in multiple types of cancer, including CRC, and has been shown to directly regulate cell growth, migration or invasion $(28,29,38)$; therefore, it is reasonable to suggest that the decreased cell proliferation and invasion observed in Lgr6 siRNA-transfected CRC cells were the result of decreased PI3K/AKT activity.

In conclusion, data from the present study demonstrated that Lgr6 was significantly upregulated in CRC.Lgr6 promoted CRC cell proliferation and migration in vitro and activated the PI3K/AKT signaling pathway. These results suggested that Lgr6 may be a predictive biomarker and a novel therapeutic target for patients with advanced CRC, and may improve the prognosis of patients.

\section{Acknowledgements}

Not applicable.

\section{Funding}

The manuscript was supported by Six Talent Peaks Program of Jiangsu Province (grant no. 2015-WSW-051), the Social Development Foundation of Nantong City (grant no.MS32016017).

\section{Availability of data and materials}

The datasets used and/or analyzed during the current study are available from the corresponding author on reasonable request.

\section{Authors' contributions}

FQ was a major contributor in writing the manuscript and analyzed the data. C-QD and L-RZ performed the histological examination of $\mathrm{CRC}$ tissues. $\mathrm{CB}$ and $\mathrm{FW}$ performed the experiments of CRC cells in vitro. JQ and Y-FL analyzed the patient data, and supervised the work of the research group.

\section{Ethics approval and consent to participate}

The present study was approved and supervised by the Research Ethics Committee of the Affiliated Hospital of Nantong University. Written informed consent was obtained from all patients.

\section{Consent for publication}

The patients have provided written informed consent for the publication of any associated data excluding identifying information, including names, initials, date of birth or hospital numbers, images.

\section{Competing interests}

The authors declare that they have no competing interests.

\section{References}

1. Chen MB, Wei MX, Han JY, Wu XY, Li C, Wang J, Shen W and Lu PH: MicroRNA-451 regulates AMPK/mTORC1 signaling and fascin1 expression in HT-29 colorectal cancer. Cell Signal 26: 102-109, 2014.

2. Siegel RL, Miller KD and Jemal A: Cancer statistics, 2017. CA Cancer J Clin 67: 7-30, 2017.

3. Gellad ZF and Provenzale D: Colorectal cancer: National and international perspective on the burden of disease and public health impact. Gastroenterology 138: 2177-2190, 2010.

4. Cristóbal I, Caramés C, Madoz-Gúrpide J, Rojo F, Aguilera O and García-Foncillas J: Downregulation of miR-214 is specific of liver metastasis in colorectal cancer and could play a role determining the metastatic niche. Int J Colorectal Dis 29: 885, 2014.

5. Herszényi L, Farinati F, Cardin R, István G, Molnár LD, Hritz I, De Paoli M, Plebani M and Tulassay Z: Tumor marker utility and prognostic relevance of cathepsin B, cathepsin L, urokinase-type plasminogen activator, plasminogen activator inhibitor type-1, CEA and CA 19-9 in colorectal cancer. BMC Cancer 8: 194, 2008.

6. Hsu SY, Liang SG and Hsueh AJ: Characterization of two LGR genes homologous to gonadotropin and thyrotropin receptors with extracellular leucine-rich repeats and a $G$ protein-coupled, seven-transmembrane region. Mol Endocrinol 12: 1830-1845, 1998.

7. Hsu SY, Kudo M, Chen T, Nakabayashi K, Bhalla A, van der Spek PJ, van Duin $M$ and Hsueh AJ: The three subfamilies of leucine-rich repeat-containing $G$ protein-coupled receptors (LGR): Identification of LGR6 and LGR7 and the signaling mechanism for LGR7. Mol Endocrinol 14: 1257-1271, 2000.

8. Leushacke M and Barker N: Lgr5 and Lgr6 as markers to study adult stem cell roles in self-renewal and cancer. Oncogene 31: 3009-3022, 2012.

9. de Lau W, Barker N, Low TY, Koo BK, Li VS, Teunissen H, Kujala P, Haegebarth A, Peters PJ, van de Wetering M, et al: Lgr5 homologues associate with Wnt receptors and mediate R-spondin signalling. Nature 476: 293-297, 2011. 
10. Carmon KS, Gong X, Lin Q, Thomas A and Liu Q: R-spondins function as ligands of the orphan receptors LGR4 and LGR5 to regulate Wnt/beta-catenin signaling. Proc Natl Acad Sci USA 108: 11452-11457, 2011.

11. Gong X, Carmon KS, Lin Q, Thomas A, Yi J and Liu Q: LGR6 is a high affinity receptor of R-spondins and potentially functions as a tumor suppressor. PLoS One 7: e37137, 2012.

12. Glinka A, Dolde C, Kirsch N, Huang YL, Kazanskaya O, Ingelfinger D, Boutros M, Cruciat CM and Niehrs C: LGR4 and LGR5 are R-spondin receptors mediating Wnt/beta-catenin and Wnt/PCP signalling. EMBO Rep 12: 1055-1061, 2011

13. Fodde R, Smits R and Clevers H: APC, signal transduction and genetic instability in colorectal cancer. Nat Rev Cancer 1: 55-67, 2001.

14. Cancer Genome Atlas Network: Comprehensive molecular characterization of human colon and rectal cancer. Nature 487: 330-337, 2012.

15. Walker F, Zhang HH, Odorizzi A and Burgess AW: LGR5 is a negative regulator of tumourigenicity, antagonizes Wnt signalling and regulates cell adhesion in colorectal cancer cell lines. PLoS One 6: e22733, 2011.

16. Wu C, Qiu S, Lu L, Zou J,Li WF, Wang O,Zhao H, Wang H, Tang J, Chen L, et al: RSPO2-LGR5 signaling has tumour-suppressive activity in colorectal cancer. Nat Commun 5: 3149, 2014.

17. Steffen JS, Simon E, Warneke V, Balschun K, Ebert M and Röcken C: LGR4 and LGR6 are differentially expressed and of putative tumor biological significance in gastric carcinoma. Virchows Arch 461: 355-365, 2012.

18. Simon E, Petke D, Böger C, Behrens HM, Warneke V, Ebert M and Röcken C: The spatial distribution of LGR5+ cells correlates with gastric cancer progression. PLoS One 7: e35486, 2012.

19. Hirsch D, Barker N, McNeil N, Hu Y, Camps J, McKinnon K, Clevers H, Ried T and Gaiser T: LGR5 positivity defines stem-like cells in colorectal cancer. Carcinogenesis 35: 849-858, 2014.

20. Parma P, Radi O, Vidal V, Chaboissier MC, Dellambra E, Valentini S, Guerra L, Schedl A and Camerino G: R-spondin1 is essential in sex determination, skin differentiation and malignancy. Nat Genet 38: 1304-1309, 2006.

21. Garcia-Closas M, Couch FJ, Lindstrom S, Michailidou K, Schmidt MK, Brook MN, Orr N, Rhie SK, Riboli E, Feigelson HS, et al: Genome-wide association studies identify four ER negative-specific breast cancer risk loci. Nat Genet 45 : 392-398. e1-e2, 2013.

22. Ren W, Lewandowski BC, Watson J, Aihara E, Iwatsuki K, Bachmanov AA, Margolskee RF and Jiang P: Single Lgr5- or Lgr6-expressing taste stem/progenitor cells generate taste bud cells ex vivo. Proc Natl Acad Sci USA 111: 16401-16406, 2014.

23. Oeztuerk-Winder F, Guinot A, Ochalek A and Ventura JJ: Regulation of human lung alveolar multipotent cells by a novel p38alpha MAPK/miR-17-92 axis. EMBO J 31: 3431-3441, 2012.

24. Snippert HJ, Haegebarth A, Kasper M, Jaks V, van Es JH, Barker N, van de Wetering M, van den Born M, Begthel $\mathrm{H}$, Vries RG, et al: Lgr6 marks stem cells in the hair follicle that generate all cell lineages of the skin. Science 327: 1385-1389, 2010 .
25. Sobin LH and Compton CC: TNM seventh edition: What's new, what's changed: Communication from the International Union Against Cancer and the American Joint Committee on Cancer. Cancer 116: 5336-5339, 2010

26. Livak KJ and Schmittgen TD: Analysis of relative gene expression data using real-time quantitative PCR and the 2(-Delta Delta C(T)) method. Methods 25: 402-408, 2001

27. Zhang J, Zhang Y,Li X, Wang H, Li Q and Liao X: MicroRNA212 inhibits colorectal cancer cell viability and invasion by directly targeting PIK3R3. Mol Med Rep 16: 7864-7872, 2017.

28. Kang DW, Lee BH, Suh YA, Choi YS, Jang SJ, Kim YM, Choi KY and Min DS: Phospholipase D1 inhibition linked to upregulation of ICAT blocks colorectal cancer growth hyperactivated by Wnt/beta-catenin and PI3K/Akt signaling. Clin Cancer Res 23: 7340-7350, 2017

29. Liu L, Gao H, Wang H, Zhang Y, Xu W, Lin S, Wang H, Wu Q and Guo J: Catalpol promotes cellular apoptosis in human HCT116 colorectal cancer cells via microRNA-200 and the downregulation of PI3K-Akt signaling pathway. Oncol Lett 14: 3741-3747, 2017.

30. Paluszczak J, Kleszcz R, Studzińska-Sroka E and Krajka-Kuźniak V: Lichen-derived caperatic acid and physodic acid inhibit Wnt signaling in colorectal cancer cells. Mol Cell Biochem 441: 109-124, 2018.

31. Jang BG, Lee C, Kim HS, Shin MS, Cheon MS, Kim JW and Kim WH: Distinct expression profile of stem cell markers, LGR5 and LGR6, in basaloid skin tumors. Virchows Arch 470: 301-310, 2017.

32. Sjöblom T, Jones S, Wood LD, Parsons DW, Lin J, Barber TD, Mandelker D, Leary RJ, Ptak J, Silliman N, et al: The consensus coding sequences of human breast and colorectal cancers. Science 314: 268-274, 2006.

33. Mokarram P, Kumar K, Brim H, Naghibalhossaini F, Saberi-firoozi M, Nouraie M, Green R, Lee E, Smoot DT and Ashktorab H: Distinct high-profile methylated genes in colorectal cancer. PLoS One 4: e7012, 2009.

34. Guinot A, Oeztuerk-Winder F and Ventura JJ: miR-17-92/p38a dysregulation enhances Wnt signaling and selects Lgr6 ${ }^{+}$cancer stem-like cells during lung adenocarcinoma progression. Cancer Res 76: 4012-4022, 2016

35. Kwon MS, Park BO, Kim HM and Kim S: Leucine-rich repeat-containing G-protein coupled receptor 5/GPR49 activates G12/13-Rho GTPase pathway. Mol Cells 36: 267-272, 2013.

36. Cardama GA, Gonzalez N, Maggio J, Menna PL and Gomez DE: Rho GTPases as therapeutic targets in cancer (Review). Int J Oncol 51: 1025-1034, 2017.

37. Coussy F, Lallemand F, Vacher S, Schnitzler A, Chemlali W, Caly M, Nicolas A, Richon S, Meseure D, El Botty R, et al: Clinical value of R-spondins in triple-negative and metaplastic breast cancers. Br J Cancer 116: 1595-1603, 2017.

38. Jia L, Luo S, Ren X, Li Y, Hu J, Liu B, Zhao L, Shan Y and Zhou H: miR-182 and miR-135b mediate the tumorigenesis and invasiveness of colorectal cancer cells via targeting ST6GALNAC2 and PI3K/AKT pathway. Dig Dis Sci 62: 3447-3459, 2017. 